\title{
Developmental screening: predictors of follow-up adherence in primary health care.
}

\author{
Joanné Christine Schoeman ${ }^{1}$, De Wet Swanepoel ${ }^{1,2,3}$, Jeannie van der Linde ${ }^{1}$
}

1. Department of Speech-Language Pathology and Audiology, University of Pretoria, South Africa

2. Ear Sciences Centre, School of Surgery, The University of Western Australia, Nedlands

3. Australia Ear Science Institute Australia, Subiaco, Australia

\begin{abstract}
Background: The importance of early identification for infants and young children with developmental delays is well established. Poor follow-up on referrals, however, undermines the effectiveness of early intervention programmes.

Objectives: To identify factors, including text message reminders, that influence follow-up adherence for early intervention after developmental screening in primary health care. A secondary objective surveyed reasons for follow-up default.

Methods: The PEDS tools were used to screen 247 high-risk children. A risk assessment questionnaire was completed with caregivers whose children were referred for speech-language and/or occupational therapy ( $\mathrm{n}=106,43 \%)$. A quasi-experimental correlational study was employed to identify risk factors for defaulting on appointments. A thematic analysis of telephonic interviews was also employed to determine reasons for follow-up defaults.

Results: Follow-up adherence was 17\%. Participants who were never married, divorced or widowed were 2.88 times more likely to attend a follow-up appointment than those who were married or living together (95\%, CI 0.97-8.63). Text message reminders did not improve follow-up. More than half $(58 \%)$ of participants who defaulted on appontments could be reached for telephonic interviews. Interviews showed that $87 \%$ of participants were unconcerned about their child's development. Other reasons for defaulting were employment, logistical issues, other responsibilities and forgetfulness.

Conclusion: Follow-up adherence for early intervention services following a positive primary health care screen was poor. Increased awareness and education regarding the importance of development for educational success is needed.

Keywords: Developmental screening, follow-up return rate, occupational therapy, PEDS tools, primary health care, speech-language therapy, text message reminders.

DOI: https://dx.doi.org/10.4314/ahs.v17i1.8

Cite as: Schoeman JC, Swanepoel DW, van der Linde J. Developmental screening: predictors of follow-up adherence in primary health care. Afri Health Sci. 2017;17(1): 52-61. https://dx.doi.org/10.4314/abs.v17i1.8
\end{abstract}

\section{Introduction}

The importance of early identification for infants, toddlers and young children with developmental delays is well established ${ }^{1-3}$. Early identification can lead to timely intervention for children at risk of developmental delays ${ }^{4}$. If support is provided early in a child's life, it may negate or minimize the negative effect of a disability on
Corresponding author:
Jeannie van der Linde, Department of Speech-Language
Pathology and Audiology,
University of Pretoria, South Africa
Communication Pathology Building,
Corner of Roper and Lynnwood road,
Hatfield campus, University of Pretroria
Tel: +27764226142
fax +27124203517
Email: jeannie.vanderlinde@up.ac.za

the child's development ${ }^{4-6}$. Early intervention positively impacts children's development, behaviour and school performance ${ }^{7}$, lessening the burden on the child, family and society ${ }^{8}$.

It is estimated that the national prevalence of moderate to severe disability in South Africa is between $5 \%$ and $6 \%$. Although the average age of identification of children with developmental delays in South Africa is not available, evidence suggests that even in developed countries, less than half of the eligible children are identified before entering school ${ }^{8}$.

In addition to late identification in South Africa, few clinicians are employed in a permanent capacity in rural communities to develop and sustain early intervention services ${ }^{10}$. Early intervention has been implemented in South Africa since 2000, but only in tertiary-level public hospitals and private practices ${ }^{9,11}$. Early intervention services would be more accessible if it were provided at primary health care settings because the majority of the population (61\%) makes use of public sector clinics as a 
first point of access to medical services ${ }^{12}$.

Employing screening and surveillance tools at primary health care settings can facilitate early identification of children with developmental delays ${ }^{13}$. This potentially enables families of all socio-economic standings to obtain early intervention for their children ${ }^{14}$. Comprehensive tracking and follow-up systems are however required to ensure that children are not only identified through screening, but also return for the appropriate assessments and intervention ${ }^{14}$. Various studies have, however, reported poor follow-up adherence for children who were referred for an early intervention evaluation ${ }^{15-18}$. Low participation rates lead to diminished effectiveness of early intervention programmes ${ }^{18}$.

Various reasons for poor follow-up adherence to early intervention services have been reported ${ }^{15,17,19,20}$. In developed countries, findings indicate that factors such as being non-English speaking, non-White race, part of a minority group, and having fewer economic resources and young, poorly educated parents, puts a family at risk of defaulting on referrals for early intervention ${ }^{17,19,20}$. In developing countries studies have found that adherence was also influenced by the distance that families had to travel to the early intervention centre ${ }^{18}$ and the fact that people forgot about appointments ${ }^{18,21,22}$.

Centralised data management and quality control monitoring systems that include accurate tracking of referred children through, among others, the use of text message reminders, have been suggested to improve follow-up ${ }^{21}$. The positive effect of repeated reminders to follow-up on referrals has been demonstrated ${ }^{22-24}$. One study found that people who received text message reminders were $50 \%$ less likely to default on appointments ${ }^{22}$. The cost of text messages to remind people to keep appointments is negligible ${ }^{22}$, making it a viable strategy in a developing country like South Africa.

The aim of this study was to determine predictive factors for follow-up adherence for early intervention, including use of text message reminders, in a primary health care context.

\section{Methods}

The current study consisted of two phases. Phase one was a quasi-experimental correlational study to determine the factors that influence follow-up adherence after a de- velopmental screening in a primary health care context. During phase two participants who did not return for a follow-up visit were contacted telephonically to survey reasons for follow-up default.

Data was collected from Stanza Bopape Clinic in Mamelodi, a township in the Tshwane district, Gauteng. Mamelodi is approximately $25 \mathrm{~km}^{2}$ with an estimated population of close to a million ${ }^{25}$. Mamelodi is characterised by diverse economic classes of people, ranging from skilled professionals to unskilled people who rely on government grants for survival ${ }^{26}$. Although Mamelodi is well established with large permanent residential areas, there exists substantial informal settlements comprising mostly of self-built houses ${ }^{27}$. The people who live in Mamelodi mostly use primary health care (PHC) clinics like Stanza Bopape Clinic as their first point of access to health care.

Ethical clearance was obtained prior to data collection from the Tshwane district research committee, department of Health as well as from the Faculty of Health Sciences and Humanities, University of Pretoria.

\section{Participants}

During a developmental screening programme, 247 children at risk of developmental delay, between the ages of 6 and 36 months were screened at a PHC clinic in Mamelodi. Of these 247 children, 106 (43\%) were referred for occupational and/or speech-language therapy. Data on the factors that influence follow-up adherence was obtained from the parents or caregivers of the young children who were referred. Participants were included in the study if they were proficient in English or Afrikaans, as these are the languages in which the researcher is proficient. If the parents were unable to answer the questions as a result of a language barrier they were excluded from the study.

Stanza Bopape Clinic was the PHC clinic closest to the homes of all of the participants. Home language distribution was Sepedi (45,3\%), isiZulu (11,3\%), Setswana $(9,4 \%)$, Tsonga $(9,4 \%)$ and other languages $(24,3 \%)$. Almost all of the participants $(99.1 \%)$ were Black and the remaining $0.9 \%$ were of another race.

\section{Material}

Developmental screening: The Parents' Evaluation of Developmental Status (PEDS) tools ${ }^{28,29}$ was used in the form of a smart phone application to screen for devel- 
opmental delays. The PEDS application is programmed to automatically score the test according to the PEDS tools scoring and interpretation algorithm ${ }^{28,29}$. Outcomes of the smart phone application have been found to correspond with the outcomes of the conventional PEDS tools in South Africa ${ }^{30}$.

The PEDS tools is a combination of the PEDS and the PEDS: Developmental Milestones (PEDS:DM) with which parental concerns as well as a child's performance on domain specific developmental milestones are identified. The PEDS tools are screening and surveillance tools that measure a child's development, behaviour and social-emotional or mental health status from birth to eight years of age. It takes less than 10 minutes to administer and score the test. The PEDS has been validated in 20 studies during 2001 to 2010 in which a total of 7213 children were assessed ${ }^{31}$. The PEDS:DM has been standardised, has high levels of validity and reliability and excellent sensitivity and specificity $(83 \%$ and $84 \%$ respectively). Furthermore, a recent study confirmed that use of the PEDS tools is feasible in South Africa ${ }^{32}$.

Risk assessment questionnaire: A risk assessment questionnaire was used to determine the risk factors for defaulting on follow-up appointments. The risk factors were chosen based on factors that other studies have investigated or recommended for future studies with regards to follow-up adherence. The risk factors were the age $^{16}$ and gender ${ }^{15,16,18,19,33-35}$ of the child, maternal and caregiver age $e^{15-17,19,21,23,35,36}$, who the primary caregiver is, marital status of caregivers ${ }^{19,20,37}$, educational qualifications $^{15-20,23,35,36}$, employment ${ }^{18,20,35}$, average household income $^{16-20,33,35,36}$, type of housing ${ }^{18}$ and number of people living in the household ${ }^{35}$. In addition, the effect of text message reminders on follow-up adherence was investigated $^{22,38}$.

Telephonic interview: Reasons for follow-up default were established by means of a telephonic interview consisting of two yes/no questions and two open-ended questions.

\section{Procedures}

Phase 1: Written parental or caregiver informed consent was obtained before collecting the data. The PEDS tools were conducted by two qualified speech-language therapists on each participant in the form of a smartphone application. The PEDS and PEDS:DM questions were asked as an interview to parents or caregivers. If the children failed the developmental screening, a risk assessment form was completed in the form of an interview with the parents or caregivers to collect data on child/ familial risk factors. Either a qualified speech-language therapist or a community health worker, who was trained to conduct the interview, completed the risk assessment form. Thereafter they were given an appointment for a follow-up visit, so that they could receive a second screen, further referral or patient education. The reason for a follow-up appointment was explained to all participants. Through random assignment, 54 (51\%) of the referred participants received a text message to remind them of their appointment five days before the scheduled appointment and again one day before the scheduled appointment. The remaining $52(49 \%)$ participants did not receive reminders. The text messages read: "Good day. This is to remind you to take <name $>$ to therapy (speech and/or occupational) on $<$ date $>$ at $<$ time $>$." It was one-way messages that were sent during the day.

If the participants defaulted on the follow-up appointments or did not make a new appointment within three months, it was assumed that they were not going to follow up on the referral. A time frame of three months was selected to give participants enough time to reschedule appointments.

Phase two: Reasons for defaulting on follow-up appointments were established by means of telephonic interviews with participants. The telephonic interviews were conducted at least three months after the appointment to allow sufficient time for follow-up. Telephone calls were made between eight and five o'clock during the week, unless the participant specifically asked to be phoned at a different time. The researcher attempted to contact each participant three times on three different days. Participants, who were unavailable during those times, were excluded from phase two of the study. Answers were recorded on a spreadsheet for later analysis.

\section{Data analysis}

Descriptive statistics were used to determine the referral rate and the adherence rate. During phase one Chisquared tests were used to identify significant associations between categorical variables. Similarly, significant differences between respondents attending a follow-up visit and those who did not, were evaluated with Wilcoxon rank tests. Spearman's rank correlation coefficients, 
with a Bonferroni adjustment for multiple correlations, were used to determine the significance of correlations between variables. Logistic regression was carried out on the data, with adherence to a follow-up visit being the dependent variable. Statistical signfiicance was set at 5\% and confidence intervals at $95 \%$ for all tests.

For phase two of the study, descriptive statistics were used to analyse the yes/no questions and thematic analysis was used to analyse the open-ended questions. Thematic analysis allowed for common trends or central themes to be identified among the participants.

\section{Results}

\section{Phase one}

A total of 106 (43\%) of the 247 at-risk children screened for developmental delay were referred for speech-language therapy and/or occupational therapy. The majority of participants $(n=78,74 \%)$ had one to three risk factors for communication delay and $26 \%(n=28)$ of participants had four or more risk factors for communication delay. Text messages to remind participants of the follow-up appointment were sent to $51 \%(n=54)$ of participants. Only 17\% (18/106) of participants returned for the follow-up appointment, of which 56\% (10/18) received text

Table 1: Participant characteristics according to adherence to follow-up appointment (OR = Odds Ratio; $\mathrm{Cl}=$ Confidence interval)

\begin{tabular}{|c|c|c|c|c|c|}
\hline Participant Characteristics & $\begin{array}{c}\text { Attended } \\
\text { Follow-up } \\
\mathrm{N}=18(\%)^{* *}\end{array}$ & $\begin{array}{c}\text { Did not Attend } \\
\text { Follow-up } \mathrm{N}= \\
88(\%)^{* *}\end{array}$ & $\begin{array}{c}\text { Total } \\
\mathrm{N}=106 \\
(\%)^{* *}\end{array}$ & $\begin{array}{c}\text { Odds Ratios (OR), } \\
(95 \% \mathrm{CI})\end{array}$ & $\mathrm{P}$ values \\
\hline \multicolumn{6}{|l|}{ Child Age } \\
\hline $6-18$ months & $8(44.4)$ & $51(58.0)$ & $59(55.7)$ & $1.72(0.61-4.83)$ & 0.293 \\
\hline $19-36$ months & $10(55.6)$ & $37(42.0)$ & $47(44.3)$ & & \\
\hline \multicolumn{6}{|l|}{ Maternal Age*** } \\
\hline $18-30$ years & $10(58.8)$ & $62(70.5)$ & $72(68.6)$ & $1.67(0.57-4.91)$ & 0.344 \\
\hline 31 years and older & $7(41.2)$ & $26(29.6)$ & $33(31.4)$ & & \\
\hline \multicolumn{6}{|l|}{ Caregiver Age*** } \\
\hline $18-30$ years & $9(50.0)$ & $52(61.9)$ & $61(59.8)$ & $1.63(0.58-4.57)$ & 0.350 \\
\hline 31 years and older & $9(50.0)$ & $32(38.1)$ & $41(40.2)$ & & \\
\hline \multicolumn{6}{|l|}{ Monthly Income ${ }^{* * * *}$} \\
\hline $0-\mathrm{R} 2000$ & $9(50.0)$ & $46(52.9)$ & $55(52.4)$ & $1.12(0.40-3.11)$ & 0.824 \\
\hline More than R2000 & $9(50.0)$ & $41(47.1)$ & $50(47.6)$ & & \\
\hline \multicolumn{6}{|l|}{ Infant Gender } \\
\hline Male & $12(66.7)$ & $51(58.0)$ & $63(59.4)$ & $0.69(0.24-2.02)$ & 0.493 \\
\hline Female & $6(33.3)$ & $37(42.0)$ & $43(40.6)$ & & \\
\hline \multicolumn{6}{|l|}{ Primary Caregiver } \\
\hline Mother, father or both parents & $13(72.2)$ & $70(79.6)$ & $83(78.3)$ & $1.50(0.47-4.78)$ & 0.492 \\
\hline Grandparents, extended family, foster parents & $5(27.8)$ & $18(20.5)$ & $23(21.7)$ & & \\
\hline \multicolumn{6}{|l|}{ Caregiver Education } \\
\hline Gr 10 or less & $5(27.8)$ & $25(28.4)$ & $30(28.3)$ & $1.03(0.33-3.21)$ & 0.957 \\
\hline Gr 11 -12, Tertiary & $13(72.2)$ & $63(71.6)$ & $76(71.7)$ & & \\
\hline \multicolumn{6}{|l|}{ Caregiver Marital Status } \\
\hline Living Together / Married & $6(33.3)$ & $52(59.1)$ & $58(54.7)$ & $2.88(0.97-8.63)$ & $0.045^{*}$ \\
\hline Never Married, Widowed or Divorced & $12(66.7)$ & $36(40.9)$ & $48(45.3)$ & & \\
\hline \multicolumn{6}{|l|}{ Text Message Reminder } \\
\hline Yes & $10(55.6)$ & $44(50.0)$ & $54(50.9)$ & $1.25(0.45-3.48)$ & 0.667 \\
\hline No & $8(44.4)$ & $44(50.0)$ & $52(49.1)$ & & \\
\hline \multicolumn{6}{|l|}{ Housing } \\
\hline Own house, Staying with others & $12(66.7)$ & $49(55.7)$ & $61(57.6)$ & $0.63(0.21-1.84)$ & 0.390 \\
\hline Own/ renting informal housing & $6(33.3)$ & $39(44.3)$ & $45(42.4)$ & & \\
\hline \multicolumn{6}{|l|}{ Number of residents per house } \\
\hline $2-4$ & $6(33.3)$ & $46(52.3)$ & $52(49.1)$ & $2.19(0.74-6.46)$ & 0.143 \\
\hline 5 or more & $12(66.7)$ & $42(47.8)$ & $54(50.9)$ & & \\
\hline \multicolumn{6}{|l|}{ Employed Primary Caregiver } \\
\hline 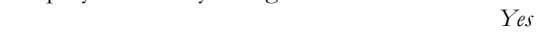 & $2(11.1)$ & $18(20.5)$ & $20(18.9)$ & $0.49(0.10-2.34)$ & 0.515 \\
\hline No & $16(88.9)$ & $70(79.5)$ & $86(81.1)$ & & \\
\hline \multicolumn{6}{|l|}{ Number of risk factors for developmental delay } \\
\hline $\begin{array}{lll}21 & 1-3\end{array}$ & & & & & \\
\hline $4+$ & $13(72.2)$ & $65(73.9)$ & $78(73.6)$ & $1.09(0.42-2.73)$ & 0.886 \\
\hline & $5(27.8)$ & $23(26.1)$ & $28(26.4)$ & & \\
\hline
\end{tabular}


message reminders (Table 1).

Spearman's rank correlation coefficients, with Bonferroni adjustment, was used to identify significant correlations between categories. The number of residents in a house was significantly correlated to caregiver marital status $(r=0.324, p=0.046)$, indicating that caregivers who were never married or were widowed or divorced lived in households with more than five residents. The number of residents in a house also significantly correlated with the type of housing $(r=0.455, \mathrm{p}<0.001)$. If a household consisted of more than five residents they were more likely to stay in informal housing than owning their own house or staying with others in a house.

Chi-squared tests and Wilcoxon rank tests indicated that the only significant association between the categorical variables and follow-up adherence was for caregiver marital status $(\mathrm{p}=0.045)$.

A logistic regression model was fitted to the data to identify predictive factors contributing to follow up adherence by participants. The only significant contributor to the odds of attending follow-up remained caregiver marital status, with respondents never married, divorced or widowed 2.88 times more likely to attend than those who were living together or married.

\section{Phase two}

Of the 88 participants who defaulted on the follow-up appointments, 51 (58\%) could be reached telephonically. Informed consent was obtained for $92 \%(n=47)$ of these participants; the remaining $8 \%(n=4)$ did not consent to an interview and were therefore excluded from phase two of the study.

The $37(42 \%)$ participants who could not be reached had telephone numbers that repeatedly went directly to voicemail ( $\mathrm{n}=18 ; 49 \%)$, did not exist $(\mathrm{n}=8 ; 22 \%)$, were not answered $(n=7 ; 19 \%)$ or were incorrect $(n=4 ; 11 \%)$.

Of the participants who received text message reminders, $43 \%(n=23)$ could not be reached telephonically. The reasons for this were that $43 \%(n=10)$ of the numbers went directly to voicemail, $26 \%(n=6)$ of the numbers had no answer, $22 \%(n=5)$ of the numbers did not exist and $9 \%(n=2)$ of the numbers were incorrect.

Participants who could be reached telephonically were asked whether they were concerned about their child's development. Forty-one participants (87\%) indicated'no' and six $(13 \%)$ indicated 'yes'. They were also asked whether they understood why their child was referred for speech and/or occupational therapy. Twenty six (55\%) of the participants indicated 'yes', 20 (43\%) of the participants indicated 'no' and one (2\%) was unable to answer because she was not the person who received the referral at the clinic.

Participants were then asked two open-ended questions, namely the reasons for being concerned or unconcerned about their child's development; and reasons for not adhering to the follow-up appointment. Central themes, together with illustrative quotes from participants who were concerned and participants who were not concerned about their child's development, are presented in Table 2

\section{Table 2: Participants who were concerned about their child's development $(n=6)$ : Themes and illustrative quotes from telephonic interviews}

\begin{tabular}{|c|c|}
\hline Themes & Quotes \\
\hline \multicolumn{2}{|c|}{ Reasons for being concerned about child's development } \\
\hline Delayed development & $\begin{array}{l}\text { She is not doing what other children of her age are doing. } \\
\text { He is not walking. }\end{array}$ \\
\hline Behaviour problems & He is learning bad things. \\
\hline \multicolumn{2}{|c|}{ Reasons for not attending the appointment } \\
\hline Employment & $\begin{array}{l}\text { I could not get off at work. } \\
\text { I had a job interview. }\end{array}$ \\
\hline Awareness & I was not aware of the appointment. \\
\hline Logistical issues & $\begin{array}{l}\text { I do not remember why I did not go, but I wanted to go. } \\
\text { We were in Limpopo (visiting family). }\end{array}$ \\
\hline
\end{tabular}




\section{Table 3: Participants who were not concerned about their child's development $(n=40)$ : Themes and illustrative quotes from telephonic interviews}

\begin{tabular}{ll}
\hline Themes & Quotes \\
\hline $\begin{array}{l}\text { Reasons for not being concerned about child's development } \\
\text { Development }\end{array}$ & She can do everything and talks fluently. \\
Health & My child is healthy and is eating well. \\
He is not sick. & I do not know. \\
I can't explain. \\
Unable to provide reason
\end{tabular}

and Table 3 respectively.

\section{Discussion}

Poverty, parental education less than the $9^{\text {th }}$ grade, unemployment, single parenthood and lack of a stable residence puts a child at risk of developmental delay ${ }^{39-41}$. Every participant in the current study had at least one risk factor for developmental delay ${ }^{39-41}$, resulting in a high referral rate of $43 \%$, similar to that of a recent study at a PHC clinic in the Tshwane district ${ }^{42}$. Although many children in this population may be in need of early intervention, $83 \%$ of children who were screened for developmental delays did not follow up on the referrals.

Text message reminders showed very little effect compared to previous studies performed in developing countries $^{22,38,43,44}$, with no significant increase in follow-up adherence. The lack of an observed effect may be explained in part by the prevalence of cellular phone turnover. Cellular phone turnover has been reported to be common in a semi-urban area in South Africa due to theft or loss $(39 \%)$ and/or damage $(28 \%)^{45}$. Of the participants who received text message reminders, $43 \%(n=23)$ could not be reached telephonically and $9.3 \%(n=5)$ of the numbers no longer existed. It is unclear whether these numbers also did not exist or were not in use at the time that the text message reminders were sent. In future, multiple contact numbers could be obtained from caregivers so that text messages could be sent to more than one recipient. Contact numbers should be verified to ensure that they are functional and owned by the client and it should be confirmed that text message reminders were received. If resources permit, a phone call plus text message reminder could be used, as this has been successful in a 
previous study ${ }^{38}$.

The only predictor for poor follow-up that could be identified from the risk assessment form was marital status. Contrary to what other studies ${ }^{19,20}$ have found, there was a significant association between caregiver marital status and follow-up adherence, with respondents never married, divorced or widowed being more likely $(p=0.045)$ to attend than caregivers who were married or lived together. Single caregivers also tended to live in informal housing with five or more residents. It may be that single caregivers feel a stronger need for support from experts as they are the sole provider and caregiver of their child. This association needs to be explored further, however.

A recurring theme in the telephonic interviews was that persons who were employed did not attend the appointment because they were unable to get leave from work. This was applicable to participants who were concerned about their child's development as well as those who were unconcerned. Poor adherence has been reported amongst employed people in other studies too ${ }^{35,46}$. Participants also defaulted on the follow-up appointment due to job interviews. High rates of unemployment exist in this research setting ${ }^{47}$, providing a possible explanation for the prioritisation of work over follow-up adherence for early intervention.

Some participants defaulted on follow-up appointments due to unforeseeable responsibilities like caring for an ill child or attending a funeral. Other participants defaulted due to difficulties with transport or because they were out of town. These reasons have also been reported in a previous study ${ }^{48}$. Some participants forgot about the follow-up appointment, as has also been reported in other studies ${ }^{21,49}$. More should be done to encourage parents to reschedule appointments if they were unable to attend. Initiatives such as community oriented primary health care may be utilised to follow up on infants and young chilldren and to create awareness on developmental delays and the importance of early intervention by means of home visits by community health workers ${ }^{50}$. Telephone call reminders and home visits by community health workers to reschedule missed appointments have been found to be successful in a hearing screening programme in South Africa ${ }^{24}$.

Participants may not have rescheduled because motivation to attend the follow-up appointments were low. Most participants $(87 \%)$ were not concerned about their child's development and more than half $(55 \%)$ of these participants indicated that they understood why their child was

African Health Sciences Vol 17 Issue 1, March, 2017 referred for occupational and/or speech-language therapy. Thus, most participants remained unconcerned about their child's development despite understanding the reasons for referral. Some parents therefore believed that if their child is healthy there is nothing to be concerned about. Mothers who do not suspect that their child may have developmental problems are less likely to adhere to programmes that provide health services ${ }^{51}$. Caregivers need to be educated on the importance of timely intervention for developmental delays.

Parent and caregiver education can perhaps be better achieved by including a parent education feature on the PEDS application. The application could provide a short explanation for the reason for referral in understandable language at the end of the screening. Written information on the importance of early intervention could be provided to parents so that they can remember the importance and reasons for the referral.

The current study provides a unique perspective on factors influencing follow-up adherence after developmental screening in South Africa. It has advanced our understanding of exploring more effective ways to improve follow up of developmentally delayed children for early intervention in urban communities. There were, however, some limitations to the study.

\section{Limitations}

A potential language barrier existed between the researcher and participants. Even though English is generally the accepted language for communication between people with different home languages ${ }^{52}$, neither English nor Afrikaans were home languages of participants, with the exception of one participant who spoke Afrikaans. This may have resulted in difficulty understanding the importance and reason for referrals. The use of community health workers to administer the PEDS tools has been found to be successful ${ }^{30}$ and future research could evaluate the effect thereof on follow-up adherence, as the community health workers speak the caregiver's language and understand the culture ${ }^{24}$.

A replication of the study with a larger sample size is also recommended. This will improve the chances of finding significant contributors to follow-up. Parental knowledge and beliefs on early childhood development may have had an effect on follow-up adherence. This should also be explored further in future research.

\section{Conclusion}


In this study early identification of possible developmental delays in most cases $(83 \%)$ did not translate to acceptable follow-up adherence for early intervention services. Participants who were never married, divorced or widowed were more likely to attend a follow-up appointment than those who were married or living together. The use of text message reminders did not improve follow-up adherence significantly. Most participants (87\%) had poor motivation for follow-up because they reported not being concerned about their child's development. Participants also did not follow up on referrals because of employment, logistical issues, other responsibilities and forgetfulness. Improving follow-up adherence for early intervention after a developmental screening is complex and requires further consideration. Parents, caregivers and communities should be educated regarding the importance and benefits of early intervention to ensure that children with developmental delays are not only identified through developmental screening but also receive timely early intervention services.

\section{Acknowledgements}

The authors would like to acknowledge Stanza Bopape Clinic, Mamelodi for their willingness to participate in the study.

\section{Conflict of interest}

None to declare.

\section{References}

1. Elbaum B. Evaluation of the Battelle Developmental Inventory, 2nd Edition, Screening Test for Use in States' Child Outcomes Measurement Systems Under the Individuals With Disabilities Education Act. J Early Interv. 2010;32(4):255-73.

2. Glascoe FP. Screening for developmental and behavioral problems. Ment Retard Dev Disabil Res Rev. 2005;11(3):173-9.

3. Meisels SJ. Can developmental screening tests identify children who are developmentally at risk? Pediatrics. 1989;83(4):578-85. PubMed

4. ToughSC, Siever JE, Leew S, Johnston DW, Benzies K, Clark D. Maternal mental health predicts risk of developmental problems at 3 years of age: follow up of a community based trial. BMC Pregnancy Childbirth. 2008; 8:16.

5. Glascoe FP. The value of parents' concerns to detect and address developmental and behavioural problems. $J$ Paediatr Child Health. 1999;35(1):1-8.
6. Scherzer AL, Chhagan M, Kauchali S, Susser E. Global perspective on early diagnosis and intervention for children with developmental delays and disabilities. Dev Med Child Neurol. 2012;54(12):1079-84.

7. Reynolds AJ, Temple JA, Robertson DL, Mann EA. Long-term Effects of an Early Childhood Intervention on Educational Achievement and Juvenile Arrest: A 15-Year Follow-up of Low-Income Children in Public Schools. J Am Med Assoc. 2001;285(18):2339.

8. Aly Z, Taj F, Ibrahim S. Missed opportunities in surveillance and screening systems to detect developmental delay: A developing country perspective. Brain Dev [Internet]. Elsevier B.V.; 2010;32(2):90-7. Available from: http://dx.doi.org/10.1016/j.braindev.2009.06.004

9. Samuels A, Slemming W, Balton S. Early Childhood Intervention in South Africa in Relation to the Developmental Systems Model. Infants Young Child. 2012;25(4):334-45. 10. South African Speech-Language-Hearing Association. Guidelines : Early Communication Intervention. Port Elizabeth; 2011.

11. Van der Linde J, Kritzinger A. Perceptions of rural primary healthcare personnel about expansion of early communication intervention. African J Prim Healthc Fam Med [Internet]. 2013;5(1):1-11. Available from: http:// www.phcfm.org/index.php/phcfm/article/view/553 12. Statistics South Africa. Use of health facilities and levels of selected health conditions in South Africa: Findings from the General Household Survey, 2011 [Internet]. Pretoris; 2013. Available from: http://www.statssa.gov. $\mathrm{za} /$ publications/report-03-00-05/ report-03-00-052011. pdf

13. Brothers KB, Glascoe FP, Robertshaw NS. PEDS: developmental milestones--an accurate brief tool for surveillance and screening. Clin Pediatr (Phila). 2008;47(3):271-9. 14. UNICEF. The State of the World's Children 2013: Children with Disabilities. 2013.

15. Wang CJ, Elliott MN, Rogowski J, Lim N, Ratner JA, Schuster MA. Factors Influencing the Enrollment of Eligible Extremely-Low-Birth-Weight Children in the Part C Early Intervention Program. Acad Pediatr [nternet]. Elsevier Ltd; 2009;9(4):283-7. Available from: http://dx.doi. org/10.1016/j.acap.2009.04.001

16. Giannoni PP, Kass PH. Risk factors associated with children lost to care in a state early childhood intervention program. Res Dev Disabil [Internet]. Elsevier Ltd; 2010;31(4):914-23. Available from: http://dx.doi. org/10.1016/j.ridd.2010.02.013

17. Clements KM, Barfield WD, Kotelchuck M, Wilber 
N. Maternal socio-economic and race/ethnic characteristics associated with early intervention participation. $\mathrm{Ma}$ tern Child Health J. 2008;12(6):708-17.

18. De Souza N, Sardessai V, Joshi K, Joshi V, Hughes M. The determinants of compliance with an early intervention programme for high-risk babies in India. Child Care Health Dev. 2006;32(1):63-72.

19. Litt JS, Perrin JM. Influence of Clinical and Sociodemographic Characteristics on Early Intervention Enrollment After NICU Discharge. J Early Interv [Internet]. 2014;36(1):37-48. Available from: http://jei.sagepub. com/cgi/doi/10.1177/1053815114555575

20. Peterson CA, Wall S, Raikes HA, Kisker EE, Swanson ME, Jerald J, et al. Early Head Start: Identifying and Serving Children with Disabilities. Topics Early Child Spec Educ. 2004;24(2):76-88.

21. Scheepers LJ, Swanepoel DW, Le Roux T. Why parents refuse newborn hearing screening and default on follow-up rescreening-A South African perspective. Int J Pediatr Otorbinolaryngol [Internet]. Elsevier Ireland Ltd; 2014;78(4):652-8. Available from: http://dx.doi. org/10.1016/j.ijporl.2014.01.026

22. Adanikin AI, Awoleke JO, Adeyiolu A. Role of reminder by text message in enhancing postnatal clinic attendance. Int J Gynecol Obstet. 2014;126(2):179-80.

23. Wall SM, Taylor NE, Liebow H, Sabatino CA, Mayer LM, Farber MZ, et al. Early Head Start and Access to Early Intervention Services: A Qualitative Investigation. Topics Early Child Spec Educ. 2005;25(4):218-32.

24. Friderichs N, Swanepoel D, Hall JW. Efficacy of a community-based infant hearing screening program utilizing existing clinic personnel in Western Cape, South Africa. Int J Pediatr Otorbinolaryngol [Internet]. Elsevier Ireland Ltd; 2012;76(4):552-9. Available from: http:// dx.doi.org/10.1016/j.ijporl.2012.01.015

25. Darkey D, Visagie J. The more things change the more they remain the same: A study on the quality of life in an informal township in Tshwane. Habitat Int [Internet]. Elsevier Ltd; 2013;39:302-9. PubMed Available from: http://dx.doi.org/10.1016/j.habitatint.2012.10.016

26. Garg AK, Mashilwane C. Waste disposal pattern of Mamelodi township in Tshwane Metropolitan Municipality. Environ Econ. 2015;6(2):91 PubMed -8.

27. Mashigo P. The lending practices of township micro-lenders and their impact on the low-income households in South Africa: a case study for Mamelodi township. NewContree. 2012;65:23-46.

28. Glascoe FP. Parents' Evaluation of Developmental Status (PEDS) [Internet]. Nolensville, TN: PEDSTest. com, LLC; 2013. Available from: www.pedstest.com 29. Glascoe FP, Robertshaw NS. PEDS: Developmental Milestones. (PEDS:DM). Nolensville, TN: PEDSTest. com, LLC; 2016.

30. Maleka BK, Van der Linde J, Glascoe FP, Swanepoel DW. Developmental screening by community health workers - evaluation of a mHealth version of the PEDS tools. Press. :1-22.

31. Macy M. The Evidence Behind Developmental Screening Instruments. Infants Young Child. 2012;25(1):19_ 61.

32. Silva MLE. A Comparison of Objective, Standarised Parent-Administered Questionnaires to that of Subjective Screening Practises for the Early Detection of Developmental Delay in At-Risk Infants. 2010.

33. Rosenberg SA, Zhang D, Robinson CC. Prevalence of developmental delays and participation in early intervention services for young children. Pediatrics. 2008;121(6):e1503-9.

34. Barfield WD, Clements KM, Lee KG, Kotelchuck M, Wilber N, Wise PH. Using linked data to assess patterns of Early Intervention (EI) referral among very low birth weight infants. Matern Child Health J. 2008;12(1):24-33.

35. Olusanya BO, Akinyemi OO. Community-based infant hearing screening in a developing country: parental uptake of follow-up services. BMC Public Health. 2009;9:66.

36. Chidiebere ODI, Uchenna E, Kenechi OS. Maternal sociodemographic factors that influence full child immunisation uptake in Nigeria. South African J Child Heal [nternet]. 2014;8(4):138. Available from: http://hmpg. co.za/index.php/sajch/article/view/1077

37. Wall SM, Taylor NE, Liebow H, Sabatino CA, Mayer LM, Farber MZ, et al. Early Head Start and Access to Early Intervention Services: A Qualitative Investigation. Topics Early Child Spec Educ. 2005;25(4):218-31.

38. Bigna JJR, Noubiap JJN, Kouanfack C, Plottel CS, Koulla-Shiro S. Effect of mobile phone reminders on follow-up medical care of children exposed to or infected with HIV in Cameroon (MORE CARE): A multicentre, single-blind, factorial, randomised controlled trial. Lancet Infect Dis [Internet]. Elsevier Ltd; 2014;14(7):600-8. Available from: http://dx.doi.org/10.1016/S14733099(14)70741-8

39. Rossetti LM. Communication Intervention: Birth to Three. 2nd ed. Cengage Learning; 2001.

40. Ozkan M, Senel S, Arslan EA, Karacan CD. The socioeconomic and biological risk factors for developmental delay in early childhood. Eur J Pediatr [In- 
ternet]. 2012;171:1815-21. Available from: http:// ovidsp.ovid.com/ovidweb.cgi? T $=$ JS\&PAGE $=$ reference $\& \mathrm{D}=$ medl $\& \mathrm{NEWS}=\mathrm{N} \& A \mathrm{~N}=22983025$

41. Hillemeier MM, Morgan PL, Farkas G, Maczuga SA. Perinatal and Socioeconomic Risk Factors for Variable and Persistent Cognitive Delay at 24 and 48 months of Age in a National Sample. Matern Child Health J. 2011;15:1001-10.

42. Van Der Linde J, Swanepoel DW, Glascoe FP, Louw EM, Vinck B. Developmental screening in South Africa: Comparing the national developmental checklist to a standardized tool. Afr Health Sci. 2015;15(1):188-96. PubMed

43. Lund S, Nielsen BB, Hemed M, Boas IM, Said A, Said $\mathrm{K}$, et al. Mobile phones improve antenatal care attendance in Zanzibar: a cluster randomized controlled trial. BMC Pregnancy Childbirth [Internet]. 2014;14:29. Available from: http://www.pubmedcentral.nih.gov/articlerender. fcgi? artid $=3898378 \&$ tool $=$ pmcentre $\&$ rendertype $=$ abstract

44. Lester RT, Ritvo P, Mills EJ, Kariri A, Karanja S, Chung $\mathrm{MH}$, et al. Effects of a mobile phone short message service on antiretroviral treatment adherence in Kenya (WelTel Kenya1): A randomised trial. Lancet. 2010;376(9755):1838-45.

45. Crankshaw T, Corless IB, Giddy J, Nicholas PK, Eichbaum Q, Butler LM. Exploring the Patterns of Use and the Feasibility of Using Cellular Phones for Clinic
Appointment Reminders and Adherence Messages in an Antiretroviral Treatment Clinic, Durban, South Africa. AIDS Patient Care STDS. 2010;24(11):729-34.

46. Adeponle AB, Obembe AO, Suleiman GT, Adeyemi OS. Missed first appointments: Prevalence and associated factors in first-time attendees at an outpatient psychiatric clinic in Nigeria. Ment Health Relig Cult. 2007;10(6):60920.

47. Statistics South Africa. Census 2011: Census in brief. Pretoria; 2012.

48. Saba AH, Warren JJ, Weber-Gasparoni K, Dawson D V. Retention of Low Income Children in Three Dental Studies Investigating Early Childhood Caries. J Health Dispar Res Pract. 2014;7(4):77-90.

49. Jamil MT, Ismail NZAN, Zulkifli A Bin, Majid NA, Van Rostenberghe H. Non-attendance to the paediatric clinics in a Malaysian tertiary hospital: A sizeable problem and identification of an efficacious intervention. J Paediatr Cbild Health. 2011;47(6):346-9.

50. Bam N, Marcus T, Hugo J, Kinkel H-F. Conceptualizing community oriented primary care (COPC) - The Tshwane, South Africa, health post model. African J Prim Heal Care Fam Med. 2013;5(1):54-6.

51. Ballantyne M, Stevens B, Guttmann A, Willan AR, Rosenbaum P. Maternal and infant predictors of attendance at Neonatal Follow-Up programmes. Child Care Health Dev. 2013;40(2):250-8.

52. Van der Merwe T. Ekonomie en meertaligheid: 'n herbesinning oor die Suid- Afrikaanse taalbeleid. Tydsker 